\title{
FROM BATHYMETRY TO BIOSHIELDS: A REVIEW OF POST-TSUNAMI ECOLOGICAL RESEARCH IN INDIA AND ITS IMPLICATIONS FOR POLICY
}

Mukherjee Nibedita ${ }^{1,2,3}$, Farid Dahdouh-Guebas ${ }^{1,2}$, Vena Kapoor ${ }^{4}$, Rohan Arthur ${ }^{4}$, Nico Koedam', Aarthi Sridhar ${ }^{5}$ and Kartik Shanker ${ }^{3,5}$

' Laboratory of Plant Biology and Nature Management, Faculty of Sciences and Bio-Engineering Sciences, Vrije Universiteit Brussel (VUB), Pleinlaan 2, 1050 Brussels, Belgium E-mail: nibedita.41282@gmail.com

2 Laboratory of Complexity and Dynamics of Tropical Systems, Département de Biologie des Organismes, Faculté des Sciences, Université Libre de Bruxelles (ULB), CP 169, Avenue F.D. Roosevelt 50, 1050 Bruxelles, Belgium

${ }^{3}$ Centre for Ecological Sciences, Indian Institute of Science, Bangalore 560 012, India

${ }^{4}$ Nature Conservation Foundation, 3076/5, 4th Cross, Gokulam Park, Mysore 570002, India

${ }^{5}$ Dakshin Foundation, Second Floor, Gowri Nilaya, Behind Baptist Hospital, Vinayak Nagar, Hebbal, Bangalore 560024, India

More than half a decade has passed since the December 26th 2004 tsunami hit the Indian coast leaving a trail of ecological, economic and human destruction in its wake. We reviewed the coastal ecological research carried out in India in the light of the tsunami. In addition, we also briefly reviewed the ecological research in other tsunami affected countries in Asia namely Sri Lanka, Indonesia, Thailand and Maldives in order to provide a broader perspective of ecological research after the tsunami. A basic search in ISI Web of Knowledge using keywords 'tsunami' and 'India' resulted in 127 peer reviewed journal articles, of which 39 articles were pertaining to ecological sciences. In comparison, Sri Lanka, Indonesia, Thailand and Maldives had, respectively, eight, four, 21 and two articles pertaining to ecology. In India, bioshields received the major share of scientific interest (14 out of 39) while only one study (each) was dedicated to corals, seagrasses, seaweeds and meiofauna, pointing to the paucity of research attention dedicated to these critical ecosystems. We noted that very few interdisciplinary studies looked at linkages between pure/applied sciences and the social sciences in India. In addition, there appears to be little correlation between the limited research that was done and its influence on policy in India. This review points to gap areas in ecological research in India and highlights the lessons learnt from research in other tsunamiaffected countries. It also provides guidance on the links between science and policy that are required for effective coastal zone management. 